\title{
Analysis on Mode of Iron Tailings Comprehensive Utilization
}

\author{
Yufeng $\mathrm{LI}^{1,2}$, Xiaoyu WANG ${ }^{2}$, Jingling $\mathrm{BAO}^{1,3}$
}

(1.Hebei Industrial University, Tianjin 300401, China;

\author{
2. North China University of Science and Technology, Tangshan 063009, China;
}

3.Tianjin Environmental Protection Bureau, Tianjin 300191, China)

Keywords: iron ore tailings resources; development and utilization of pattern; circular economy; overall utilization

\begin{abstract}
Through the analysis of current development and utilization of iron ore tailings resources in China, we can summarize the present development and utilization pattern of iron ore tailings resources. According to the theory of sustainable development, people can put forward three connotations of iron ore tailings resources, which are "efficient utilization", "clean utilization" and "sustainable utilization". According to the three production theories and circular economy theories, people can conclude that the pattern of development and utilization is "overall utilization".

People transform the environment in order to raise the living conditions, however causing severe ecological damage and environmental pollution, due to the limitations of the existing scientific and technological level and the human cognitive ability and now people start to reconsider their past behaviors and have serious reflection on it after realizing the butterfly effect causing by the transformation and conquest of nature and the rising of environmental problems such as "Ten major environmental hazards”, Ozone layer destruction, Acid deposition and global warming. Therefore, this paper aims to give some directions development and utilization of iron tailings by using some theories such as Circular economy theory, three kinds of production theory and so on under the background of "green mines".
\end{abstract}

\section{The Situation of development and utilization of iron ore tailings}

\subsection{Overview of iron ore tailings Iron}

According to the mineral composition of iron tailings, tailings have complex composition, according to the content of the associated elements, iron tailings generally are divided into two categories that are single and multi-etals iron tailings metals iron tailings. According to the different quantity of mineral contain in minerals calcium, magnesium, aluminum, silicon, a single metallic can be divided into Anshan iron ore tailings, Magang iron tailings, tailings and Jiuquan Iron and Steel, Handan Iron. While Anshan iron ore tailings pile stocks ups to a maximum. Iron tailings are generally divided into high silicon iron tailings, high calcium and high magnesium ferric iron tailings. The use of various types of iron ore tailings are following in Table 1.

Table 1 The use of various types of iron tailings

\begin{tabular}{|c|c|c|}
\hline Type iron tailings & The main ingredient & The main purpose \\
\hline High Silicon & $\mathrm{SiO}_{2} 、 \mathrm{Al}_{2} \mathrm{O}_{3} 、 \mathrm{CaO} 、 \mathrm{MgO}$ & $\begin{array}{l}\text { it is used for making brick, glass - ceramics, road base, } \\
\text { ceramic, preparation of mineral fertilizers, the development } \\
\text { of concrete }\end{array}$ \\
\hline High Aluminum & $\mathrm{Cu} 、 \mathrm{P} 、 \mathrm{~S} 、 \mathrm{Al}_{2} \mathrm{O}_{3}$ & It is used for making castable refractory, insulation materials. \\
\hline High calcium, High magnesium & $\mathrm{CaO} 、 \mathrm{MgO} 、 \mathrm{~S} 、 \mathrm{Cu} 、 \mathrm{Ni} 、 \mathrm{Zn} 、 \mathrm{~Pb}$ & It is used for making System clinker, production of cement. \\
\hline
\end{tabular}

\section{2 Exploitation and utilization of Iron Tailing Resources}

The comprehensive utilization of iron tailing resources in China has a great development in recent years. Facing with contradictions of supply and demand and increasing dependence foreign trade, many domestic scholars and enterprises research on iron tailing resource utilization status and utilization direction etc. The utilization of iron tailing is shown in Table 2[1-7]. According to the literature, the production of concrete and cement are used widely. 
Table 2 Utilization of iron tailings

\begin{tabular}{|c|c|c|}
\hline Iron tailings Features & Iron tailings use direction & Utilization Characteristics \\
\hline Valuable high metal content & Recovery of valuable metal use & Improve the utilization of secondary resources \\
\hline Valuable low metal content & Filling Underground & The most direct way to use tailings \\
\hline $\begin{array}{l}\text { physicochemical properties and } \\
\text { titanium element content itself }\end{array}$ & Brick & Tailings consumption, wide product sales \\
\hline Higher $\mathrm{SiO} 2$ content & Made into glass-ceramics & The high amount of tailings, high value products \\
\hline Si, Al, Ca higher levels & Cement Production & Reduce the production cost of cement \\
\hline Most iron ore tailings & As roadbed aggregate & $\begin{array}{l}\text { Tailings utilization is high, without too much of the } \\
\text { tailings processing, economic, social and } \\
\text { environmental benefits significant }\end{array}$ \\
\hline $\begin{array}{l}\text { It contains large amounts of trace } \\
\text { elements }\end{array}$ & $\begin{array}{l}\text { Used as mineral fertilizers and soil } \\
\text { improvers }\end{array}$ & Improve soil quality, and promote vegetation growth \\
\hline
\end{tabular}

From the perspective of literature, the recycling technology has made great progress while in the process of re-election. While the results are not satisfying, 1845 important mines in China have been investigated, and the results are shown in Table 3. Most mines have a recovery of valuable components, the comprehensive utilization of useful components is more than $50 \%$ and the mine is less than $15 \%$, the comprehensive utilization of useful components which is more than $70 \%$ are accounting for only $2 \%$. Useful group of unused points has been taken into the tailing, it not only cause resource wasted, but increase the negative impact on the environment.

Table 3 The use of useful components in the mine

\begin{tabular}{lccc}
\hline Utilization of useful components & $\geq 70 \%$ & $\geq 50 \%$ & $\leq 25 \%$ \\
\hline The number of mines & 36 & 276 & 1384 \\
Accounting for the proportion of the total surveyed mine & $2 \%$ & $15 \%$ & $75 \%$ \\
\hline
\end{tabular}

On the whole, China's comprehensive utilization of tailings is still very low. There is a big gap compared with developed countries. Comprehensive utilization of resources remains to be done.

\section{Current development and utilization models of iron tailings resources}

At present, the development and utilization models of iron tailings resources are return model, absolute consumption model and other modes, and the advantages and disadvantages of each development model are compared as shown in Table 4.

Table 4 Comparison of the development and utilization model of iron tailings

\begin{tabular}{|c|c|c|c|}
\hline Model & Return model & $\begin{array}{c}\text { Absolute consumption model } \\
\text { (to be filled or to product building materials) }\end{array}$ & $\begin{array}{c}\text { Other models } \\
\text { (land reclamation or as fertilizer) }\end{array}$ \\
\hline Conditions & $\begin{array}{l}\text { Technologies are feasible and } \\
\text { economy is reasonable }\end{array}$ & $\begin{array}{l}\text { Transport radius can not be too large, and the } \\
\text { useful component is very small }\end{array}$ & $\begin{array}{l}\text { Suitable for plants and corps } \\
\text { growth, }\end{array}$ \\
\hline Advantages & $\begin{array}{l}\text { Make full use of resources and } \\
\text { ease the supply pressure }\end{array}$ & $\begin{array}{l}\text { Thoroughly solve the problem of resources } \\
\text { and environment }\end{array}$ & $\begin{array}{l}\text { Improve the ecological } \\
\text { environment }\end{array}$ \\
\hline Disadvantages & $\begin{array}{l}\text { Cause secondary- tailing } \\
\text { problems and environmental } \\
\text { problems }\end{array}$ & Product competitiveness is uncertain & $\begin{array}{c}\text { Some danger may hide in dam } \\
\text { safety }\end{array}$ \\
\hline Available degree & $\begin{array}{l}\text { About accounts fro } 20 \% \text { of the } \\
\text { total tailings }\end{array}$ & About accounts fro $80 \%$ of the total tailings & Individual case \\
\hline
\end{tabular}

Return model is commonly used for the mines exploitation. Most of the mines are working based on traditional process and the iron ore tailings recon centration process, namely in iron tailings, which has a re-election before tailings are transported to tailings dam, then the remaining will be transported to tailings dam as well. It makes full use of resources and ease the supply pressure, but it does not fundamentally solve the problem of stacking of the iron tailings; absolute consumption model means the mining areas are to be filled or to product building materials. It can completely solve the environmental problems caused by iron tailings impoundment, but the transport radius should not be too large; other models such as land reclamation or as fertilizer, especially as fertilizer or soil amendment, it is an individual case that can not be used generally due to requirements of iron tailings for plants growth. 


\section{The resource exploitation and utilization and model analysis of iron tailings}

\subsection{Analysis on the resource exploitation and utilization of 3.1 iron tailings}

The key point to achieve the mine production without tailings ultimately depends on the overall utilization of iron tailings in the construction process of "Green mine". It should be based on the specific characteristics of tailings resources to research and develop different levels of the overall utilization of products and to achieve the best comprehensive benefits of iron tailings resource development and utilization. Iron tailings resource development and utilization can be expressed as: "separate the useful components of iron tailings through advanced mineral processing technology and other effective means and to product multiple- value commodity ore as far as possible. By means of recycling waste into treasure, making a thing with multi uses, turning harm into good to use low level and high level using, so as to achieve a comprehensive, full and reasonable use of the iron tailings." Its connotation is "efficient use", "clean utilization" and "sustainable utilization"'". Its connotation is shown in table 5.

Table 5 Connotation representation of iron tailings resource development and utilization

\begin{tabular}{|c|c|c|c|}
\hline Connotations & Consideration aspects & Connotation expression & The results of utilization \\
\hline $\begin{array}{l}\text { Efficient } \\
\text { utilization }\end{array}$ & $\begin{array}{l}\text { From the perspective of } \\
\text { science and technology } \\
\text { and economy. }\end{array}$ & $\begin{array}{l}\text { It means the utilization rate should be maximized } \\
\text { to make the best use of resources. }\end{array}$ & $\begin{array}{l}\text { It reflects the advancement of } \\
\text { technology and the utilization value } \\
\text { of iron ore tailings resource. }\end{array}$ \\
\hline $\begin{array}{l}\text { Clean } \\
\text { utilization }\end{array}$ & $\begin{array}{l}\text { From the perspective of } \\
\text { natural environment. }\end{array}$ & $\begin{array}{l}\text { It means do not produce waste or produce less } \\
\text { waste as far as possible at the end of production. }\end{array}$ & It cannot cause secondary pollution. \\
\hline $\begin{array}{l}\text { Sustainable } \\
\text { utilization }\end{array}$ & $\begin{array}{l}\text { From the perspective of } \\
\text { society. }\end{array}$ & $\begin{array}{l}\text { It means people should stop overdevelopment } \\
\text { and blind development. If it does not meet } \\
\text { utilization requirements, then wait until it meets } \\
\text { the requirements. }\end{array}$ & People should make it go further. \\
\hline
\end{tabular}

\subsection{Analysis on the exploitation and utilization model of iron tailings}

Traditional economic mode of resource utilization is extensive and one-time, which gained the economic quantity growth by turning resources into the trash. This mode is no suitable for current resources exploitation and utilization. The environment system on earth has some self-purification capacity and environmental carrying capacity, but it cannot absorb unlimited consumptive waste. Thus, in order to maintain the healthy operation of the industrial chain, the exploitation and utilization of iron tailings should adopt the exploitation mode of circular economy as shown in Figure 1 [8] which has characteristics of low mining, low input, high utilization and low emission. And it sticks to the principle of "reduction, reuse and resources". "Reduction" is to reduce energy and resource as much as possible in the input process; "Reuse" requests enterprises to increase product durability in the production process to reuse products with their former functions; "resources" is to turn waste into resources and reuse them to reduce the amount of final disposal in the output process.

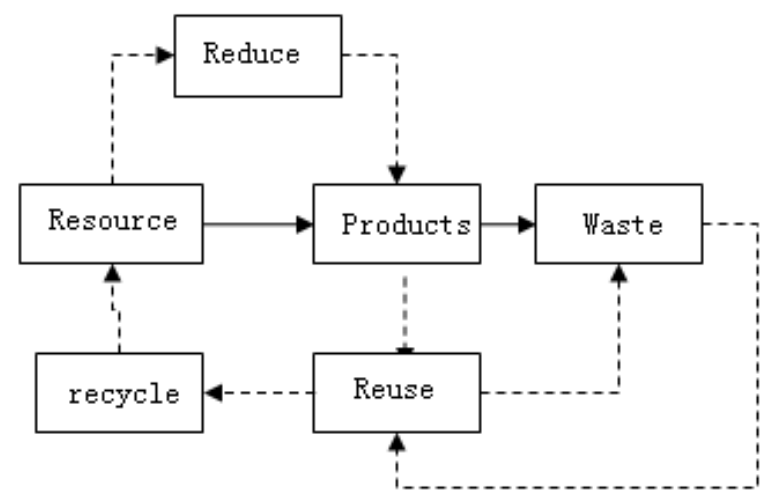

Figure 1. The exploitation mode of circular economy

The theory of circular economy requires that "save resources in the input end as far as possible, and make the impact towards the environment as little as possible". Three kinds of production theory [9] are the theories of sustainable development with the requirements that "the production of 
material goods, human and environment should adapt to each other which form a ring structure. Any kind of malformation of production (unlimited expanding or shrinking) and any kind of imbalance of the restrictive relation will do harm to the concordance and sustainability of human society". According to the environmental attribute of iron tailings resources, the development and utilization must "be used as a whole" in order to avoid the "twice pollution".

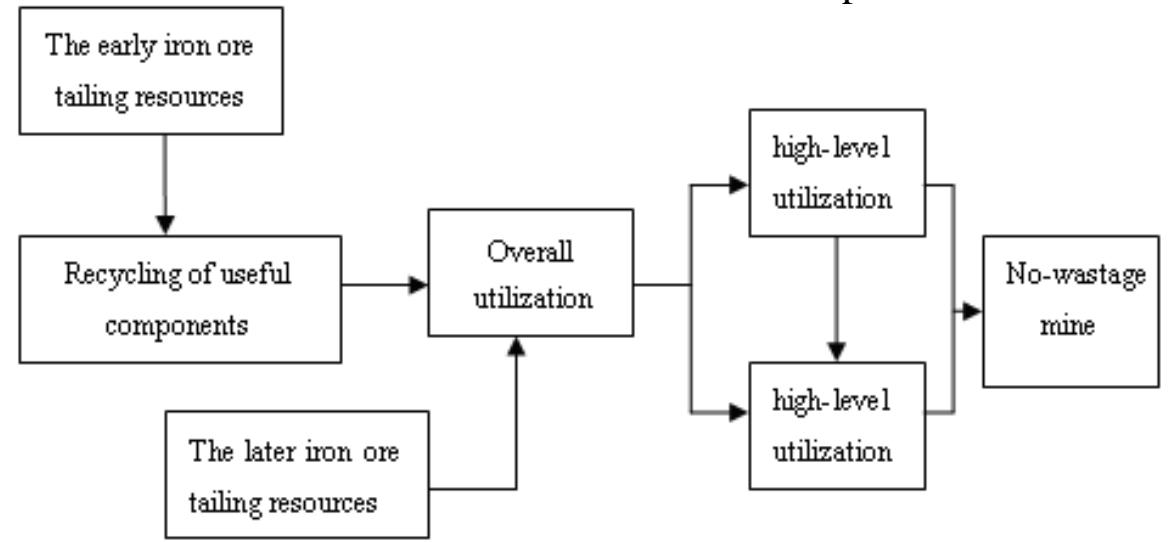

Figure2. Schematic diagram of the specific plan of iron tailing resources

We should consider the differences between before and after implementation of the green mines, when exploiting and utilizing iron tailing resources. Therefore, according to the implement time of green mines, the iron tailing resources is divided into two parts: one part is early iron tailing resources produced before the implementation of green mines, making up the majority of the total resources; in order to distinguish from the former one, this part is called late iron tailing resources produced after the implementation of green mines, making up the small proportion of the total resources. For the late iron tailing resources, mining enterprises have recycled the useful components during the production process which can be directly used; for the early iron tailing resources, we should firstly select and recycle the useful components and then utilize them. That is to recycle metal elements and extract non metallic minerals. During this process, coarse particle materials in iron tailing resources should be separated and used as aggregates for building, instead of gravel and sand. Then, select and recycle the useful components (metal or non-metal components) from the fine iron tailing resources; next, deal with the remaining part of the processing and product different grades of building materials or curing used as filling materials for filling useless iron tailings or tailings reclamation technology research. Thus, there are following three different plans for the exploitation and utilization of iron tailing resources: low-level utilization, high-level utilization, high-level and low-level combination utilization. The schematic diagram of the specific plan of iron tailing resources is shown as figure 2.

\section{4 suggestions for comprehensive utilization of iron tailings}

\subsection{Doing a good job in market research, to find out the situation of iron tailings resources}

Doing research of the classification according to the characteristics of iron tailings in different regions, to find out the ailing stockpiles in various areas, basic types of tailings, grain size composition, content and harmful components content of a variety of useful minerals and non-metallic mineral, according to the characteristics of geographical and different types of tailings, comprehensive utilization of tailings are put forward from the point of view of technology, economy, resources and environment, a more reasonable way. At the same time, making market investigation and research of comprehensive utilization of tailings products including the market price of tailings comprehensive utilization of products, and their competitiveness in the market.

4.2 Doing a good job in experimental research, increasing the iron tailings resource utilization technology research and development efforts

Making use of tests and researches, increasing technology development of the high added value products, exploring the best development scheme of iron tailings resource,making the tailings with maximum resources and economic benefits, at the same time, minimize environmental harm caused 
by the tailings utilization, recovery useful elements as much as possible, reducing waste of mineral resources of the country. At the same time,removal the harmful impurities, improve the comprehensive product quality of tailings utilization, then achieving the whole benefit including resources, economic, environmental and social things .

\subsection{Improve relative legal system}

In the system of iron tailings resource exploitation and utilization, government, mine enterprise, development and utilization enterprise and scientific and technical have different position and responsibilities. Especially the government plays the most important role. The government should give priority to the social benefits and make relative policies, laws and regulations, actively lead social investment, make full use of the developing and utilizing enthusiasm of enterprises and provide the fund and person guarantee for exploitation and utilization of iron tailings resource. The government should invest more money, launch scientific researching fund projects, and actively guide scientific researchers to do scientific researches and improve the researchers enthusiasm in technique research and development to provide the technical guarantee for exploitation and utilization of iron tailings resource.

\section{Conclusions}

Iron tailings resource exploitation model adopt the model of overall utilization. Firstly, analyzing the characteristics of iron tailings structural composition and its distributing disciplinarian in this region; what's more, combining economic development level of various regions with maturity degree of iron tailings exploitation technology, exerting this model through experiment and research, as well as current utilization status; finally, adhering to principles of fully utilizing resources, maximizing the benefits of iron tailings resources, decreasing land occupation and useful resource loss, and non-secondary pollution, pursuing comprehensive analysis and research from technical, economic, ecological environment, social benefits and other aspects to determine its optimal utilization in different regions, realize the overall utilization of iron tailings resources, and achieve the purpose of non-wasting mining.

\section{References}

[1] Xiao Liguang, Jin Hong, Cui Zhengxu. The present situation of comprehensive utilization of iron tailings at home and abroad [J]. Journal of Jilin Architecture and Civil Engineering Institute

[2] Liu Lu, Zheng Wei, Li Pan, et al. Research and utilization status of iron tailings brick [J]. Sichuan nonferrous metals, 2008, 03:36-40

[3] Guo Mingbin. Study on the preparation of glass ceramics by iron tailings [J]. mining express, 2006,05:21-23.

[4] Wan Lei, Yi Longsheng, Wang Zhou. Research and development of mine used as roadbed material for iron tailings in Jinshan shop [J]. mining research and development, 2014,04:88-91.

[5] Qiao Shuang, Zhu Yanmei, Liu Xiao. Iron ore tailings comprehensive utilization in cement production of modern mining [J]., 2009,09:120-122.

[6] He Jiaxia. Miaogou Iron Mine Tailings reclamation practice [J]. China mine engineering, 2009,06:18-20.

[7] Wang Xibing, Lian min Jie, Lv Xianjun, et al. Beiminghe clean integrated technology of [J]. production of metal mine, 2003,08:45-47.

[8] Liu Xueqian, Yang Duogui, Zhou Zhitian, et al. Research on the issue of sustainable development [M]. Beijing: Science Press, 2010

[9] Ye Wenhu, Zhang Yong. Environmental Management Science[M]. Second Edition. Beijing: Higher Education Press, 2006 